\title{
Studies on antidyslipidemic effects of Morinda citrifolia (Noni) fruit, leaves and root extracts
}

\author{
Saf-ur Rehman Mandukhail ${ }^{1,2}$, Nauman Aziz ${ }^{1}$, Anwarul-Hassan Gilani ${ }^{1,3^{*}}$
}

\begin{abstract}
Background: The objective of present study was to provide the pharmacological basis for the medicinal use of Morinda citrifolia Linn in dyslipidemia using the aqueous-ethanolic extracts of its fruits (Mc.Cr.F), leaves (Mc.Cr.L) and roots (Mc.Cr.R).

Results: Mc.Cr.F, Mc.Cr.L and Mc.Cr.R showed antidyslipidemic effects in both triton (WR-1339) and high fat dietinduced dyslipidemic rat models to variable extents. All three extracts caused reduction in total cholesterol and triglyceride levels in triton-induced dyslipidemia. In high fat diet-induced dyslipidemia all these extracts caused significant reduction in total cholesterol, triglyceride, low density lipoprotein-cholesterol (LDL-C), atherogenic index and TC/HDL ratio. Mc.Cr.R extract also caused increase in high density lipoprotein-cholesterol (HDL-C). The Mc.Cr.L and Mc.Cr.R reduced gain in body weight with a reduction in daily diet consumption but Mc.Cr.F had no effect on body weight and daily diet consumption.

Conclusions: These data indicate that the antidyslipidemic effect of the plant extracts was meditated through the inhibition of biosynthesis, absorption and secretion of lipids. This may be possibly due partly to the presence of antioxidant constituents in this plant. Therefore, this study rationalizes the medicinal use of Morinda citrifolia in dyslipidemia.
\end{abstract}

\section{Background}

Dyslipidemia is an independent and modifiable risk factor for cardiovascular diseases. Its prevalence is growing not only in developed countries but also in developing countries [1]. Treatment of dyslipidemia reduces cardiovascular events [2]. The modern pharmacological therapy for abnormal lipids is effective but is costly and associated with side-effects [3] leading to patient incompliance. Therefore, alternative therapies particularly, herbal based are being explored. Morinda citrifolia Linn (Fam. Rubiaceae) is commonly known as Noni. Different parts of the plant including fruit, leaves, root, stem and bark are used in folk medicine in Polynesia, Tahiti, Southeast Asia, Australia and Hawaii. It has been shown that these are effective against minimizing the symptoms of life style-related diseases such as atherosclerosis [4], hypertension [5] and other vascular disorders [4], stroke [6], diabetes

\footnotetext{
* Correspondence: anwar.gilani@aku.edu

'Natural Product Research Division, Department of Biological and Biomedical Sciences, Aga Khan University Medical College, Karachi 74800, Pakistan

Full list of author information is available at the end of the article
}

and cancer [7]. Furthermore, Noni juice, a popular beverage is known to contain some antioxidative and anti-inflammatory ingredients [5].

Morinda citrifolia, has been reported to possess vasodilatory [8,9], antioxidant [10] antitumor [11] and Angiotensin Converting Enzyme inhibitor activities[12]. It is an edible plant and its fruit juice is a popular drink. Almost all parts of this plant have some medicinal value and have been widely studied phytochemically [see additional file 1].

Recently we have reported that antispasmodic and vasodilatory activities of Morinda citrifolia root extract are mediated through blockade of voltage-dependent calcium channels [9]. However, the plant is not widely studied for its antidyslipidemic effects except a preliminary report [13]. Therefore, the objective of the present study was to investigate the antidyslipidemic effect of Morinda citrifolia in Triton WR 1339 and high fat dietinduced dyslipidemia rat models to rationalize its medicinal use in cardiovascular disorders. 


\section{Materials and methods Plant material}

The vacuum dried $70 \%$ aqueous-ethanolic extract of Morinda citrifolia fruit, leaves and roots were gifted by the Sami Labs Limited 19/1, 19/2, 1st Main II Phase, Peenya Industrial Area, Bangalor-560 058, India. The extracts were prepared by following procedure as described by the manufacturer. Dried leaves, fruit and roots of Morinda citrifolia were procured from a reputed herb supplier in Southern India. The leaves, fruits and roots were chopped and ground by hammer mill and passed through 20 mesh screen. The powder $(12 \mathrm{Kg})$ was extracted with $70 \%$ ethanol $(48 \mathrm{~L})$ at $70^{\circ} \mathrm{C}$ for 3 hours and filtered. The procedure repeated twice and all filtrates combined and evaporated under vacuum. The dried extracts were packed in polythene bags with nitrogen purge.

\section{Drugs and standards}

The following reference chemicals were obtained from the source specified: Triton (tyloxapol), Cholic acid, cholesterol (Sigma Chemical Company, ST Louis, MO, USA) and diethylether (Sigma-Aldrich Chemie $\mathrm{GmbH}$, Germany). Commercial Randox diagnostic kits were used for serum analyses of total cholesterol (TC), triglyceride (TG), high density lipoprotein-cholesterol (HDLC) and glucose level (Randox Laboratories Ltd., Co. Antrim, UK). All chemicals used were of the highest purity grade.

\section{Animals}

Sprague-Dawley (SD) rats (180-220 g) and mice (20-25 g) of either sex were obtained from the animal house of the Aga Khan University, Karachi. The animals were housed in constant room temperature $\left(23-25^{\circ} \mathrm{C}\right)$, kept in plastic cages $\left(47 \times 34 \times 18 \mathrm{~cm}^{3}\right)$ with sawdust (renewed after every $48 \mathrm{~h}$ ) and had free access to food and water. Rats were starved for $16 \mathrm{hrs}$ prior to experiment, anaesthetized with diethyl ether by inhalation and blood was collected via cardiac puncture. Experiments performed with the rulings of the Institute of Laboratory Animal Resources, Commission on Life Sciences [14].

\section{Preparation of diet}

The following two types of diets were prepared.

1. Normal diet: The normal diet was prepared at the animal house of the Aga Khan University (AKU), Karachi. The standard diet consists of flour $(5 \mathrm{~kg})$, chokar (5 kg), salt (75 g), nutrivet L (33 g), molasses $(150 \mathrm{~g})$, potassium meta bisulphate $(15 \mathrm{~g})$, fish meal (2.25 kg), powdered milk (2 kg) and oil (500 g) for a total of about $15 \mathrm{~kg}$ of the food material.
2. Atherogenic diet: Cholesterol $(2 \% \mathrm{w} / \mathrm{w})$, cholic acid $(0.5 \% \mathrm{w} / \mathrm{w})$ and butter fat $(5 \% \mathrm{w} / \mathrm{w})$ were added to normal diet, as described by Ichihashi [15] with slight modification.

All measures were taken to ensure the uniform mixing of additives in dry ingredients of the diet before kneading.

\section{Triton WR 1339-induced model of hyperlipidemia}

The tyloxapol-induced hyperlipidemic model earlier described by Khanna [16] was followed with slight modifications. Male SD rats weighing 180-220 g caged in uniform hygienic conditions and kept on standard pellet diet and water ad libitum. The rats were randomly divided into 8 groups, each containing 6 rats, 1) control group, 2) tritonized group (untreated) and 3-8) treated groups with plant materials (Mc.Cr.F, Mc.Cr.R and Mc. Cr.L). After 10 days of the treatment, all animals were fasted for $7 \mathrm{~h}$ and group 1 received saline $(10 \mathrm{ml} / \mathrm{kg}$; i.p.), while groups $2-8$ were given tyloxapol $(500 \mathrm{mg} / \mathrm{kg}$; i.p.). On the next day, rats were anaesthetized with diethylether by inhalation and blood was collected via cardiac puncture for analysis of serum total cholesterol and triglycerides.

\section{High fat diet-induced model}

The high fat diet-induced dyslipidemic model was used as earlier described [17] with slight modifications after pilot studies. The adult SD rats (180-220 g) were randomly divided into different groups, each containing 6 rats. Control group was given normal diet (served as normal control), untreated group given atherogenic diet (atherogenic control) and treated groups were given atherogenic diet plus drug administered orally. All the groups of animals had free access to water and diet. The diet consumption was monitored daily and the gain in body weight was monitored weekly. At the end of the treatment, rats were fasted for $16 \mathrm{hrs}$, anaesthetized with diethyl ether by inhalation, blood was collected via cardiac puncture and serum analyzed for lipid profile and glucose level.

\section{Biochemical studies}

Estimation of lipid profile and glucose level

For the determination of serum total cholesterol, high density lipoprotein cholesterol, triglyceride and glucose, a methods described by the manufacture (Randox Laboratories Ltd., Co. Antrim, UK.) was used. For this method test sample (serum), standard and blank were pipetted using a micropipette in to eppendorf tube. The reaction mixtures were mixed well and incubated at $20-25^{\circ} \mathrm{C}$. After incubation, $0.25 \mathrm{ml}$ of each reaction 
mixture was poured in 96 well plates and the absorbance was read at $490 \mathrm{~nm}$ against the reagent blank in micro plate reader (Model 680 Bio-Rad Laboratories UK Ltd). The concentration of absorbance was calculated from the slope of concentration curve of the standards.

Estimation of $L D L-C, T C / H D L$ and atherogenic index

These result were calculated indirectly by using formula describe by [18].

$\mathrm{LDL}=\mathrm{TC}-\mathrm{HDL}-\mathrm{TG} / 5$ and Atherogenic index $=$ TC-HDL/HDL.

\section{Acute toxicity}

The test was performed as described earlier [18]. Animals were divided in different groups of 5 mice each and were administered increasing doses of the plant extracts $(3,5$, $10 \mathrm{~g} / \mathrm{kg}$, p.o.), in $10 \mathrm{ml} / \mathrm{kg}$ volume. Another group of mice was administered saline $(10 \mathrm{ml} / \mathrm{kg}$, p.o. $)$ served as a negative control. The mice were allowed food and water ad libitum during a $24 \mathrm{hr}$ test period and kept under regular observation for gross behavioural changes and mortality.

\section{Data analysis}

All data were expressed as mean \pm standard error of mean (SEM, $\mathrm{n}=$ number of experiments) and $\mathrm{EC}_{50}$ values are given as geometric mean with $95 \%$ confidence intervals (CI). One-way Analysis of Variance (one-way ANOVA) was used to compare the differences in means of more than two groups, followed by Tukey post-test to determine significant differences among the pairs. $\mathrm{P}$-values less than $0.05(\mathrm{p}<0.05)$ were considered as statistically significant. All the graphs, calculation and statistical analyses were performed using GraphPad Prism software version 4.00 for Windows (GraphPad Software, San Diego California USA, http://www.graphpad.com).

\section{Results}

\section{Effect of Morinda citrifolia extracts on tyloxapol-induced} hyperlipidemia

Administration of tyloxapol (triton WR-1339) caused a significant increase $(\mathrm{p}<0.001)$ in serum total cholesterol and triglyceride of tritonized group as compared to animals in the control group. Pretreatment of the rats with Mc.Cr.F $(1000 \mathrm{mg} / \mathrm{kg})$, Mc.Cr.L $(1000 \mathrm{mg} / \mathrm{kg})$ and Mc. Cr.R $(500 \mathrm{mg} / \mathrm{kg})$ caused significant reduction in cholesterol and triglyceride level. The data are summarized in Table 1.

\section{Effect of Fruit extract on high fat diet-induced dyslipidemia}

The intake of atherogenic diet increased serum total cholesterol (TC), triglyceride, LDL-C, TC/HDL ratio, atherogenic index and glucose level as compared to the control group. The oral administration of fruit extract $(1000 \mathrm{mg} / \mathrm{kg})$ with atherogenic diet prevented the rise in
Table 1 Effect of Morinda citrifolia extracts on tyloxapolinduced hyperlipidemia

\begin{tabular}{lll}
\hline Groups & $\begin{array}{l}\text { Total cholesterol } \\
\text { (mg/dl) }\end{array}$ & $\begin{array}{l}\text { Triglyceride } \\
\text { (mg/dl) }\end{array}$ \\
\hline Control & $66.44 \pm 4.84$ & $94.36 \pm 8.83$ \\
Tritonized & $878.76 \pm 15.20$ & $5177.73 \pm 318.92$ \\
Treatments & & \\
$\quad$ Mc.Cr.F $1000 \mathrm{mg} / \mathrm{kg} /$ day & $565.83 \pm 40.72^{* *}$ & $3457.30 \pm 275.13^{*}$ \\
$\quad$ Mc.Cr.F $500 \mathrm{mg} / \mathrm{kg} /$ day & $777.11 \pm 80.32$ & $4647.44 \pm 237.38$ \\
$\quad$ Mc.Cr.L $1000 \mathrm{mg} / \mathrm{kg} /$ day & $620.32 \pm 39.32^{*}$ & $3693.55 \pm 70.52^{*}$ \\
$\quad$ Mc.Cr.L $500 \mathrm{mg} / \mathrm{kg} /$ day & $699.00 \pm 25.87$ & $4110.84 \pm 338.59$ \\
$\quad$ Mc.Cr.R $500 \mathrm{mg} / \mathrm{kg} /$ day & $540.69 \pm 107.57^{* *}$ & $2997.02 \pm 669.2^{* * *}$ \\
Mc.Cr.R $300 \mathrm{mg} / \mathrm{kg} /$ day & $844.0091 \pm 44.32$ & $4849.91 \pm 167.52$
\end{tabular}

Vale shown are mean \pm S.E.M of 6 determinations

One-way ANOVA followed by Tukey post-test

${ }^{*} \mathrm{P}<0.05$, ${ }^{*} \mathrm{P}<0.01$ and ${ }^{* * *} \mathrm{P}<0.001$ compared to atherogenic group.

serum TC, LDL-C, TC/HDL ratio and atherogenic index. The treatment with the fruit extract had no significant effect $(p>0.05)$ on the HDL-C and glucose levels as compared to the atherogenic group. However, there was no effect seen on body weight and daily diet consumption $(p>0.05)$. The data are summarized in Table 2.

\section{Effect of leaves extract on high fat diet-induced dyslipidemia}

The TC, triglyceride, LDL-C, TC/HDL ratio, atherogenic index and glucose levels of the atherogenic group were significantly increased as compared to the control group. Oral administration of leaves extract $(1000 \mathrm{mg} /$ $\mathrm{kg}$ ) with atherogenic diet prevented the rise of serum TC, LDL-C, TC/HDL ratio, atherogenic index and

Table 2 Effect of Morinda citrifolia fruit extract $(1000 \mathrm{mg} / \mathrm{kg})$ on high fat diet-induced hyperlipidemia

\begin{tabular}{llll}
\hline Parameters & Control & Atherogenic & Treated \\
\hline Total cholesterol $(\mathrm{mg} / \mathrm{dl})$ & $67.48 \pm$ & $438.50 \pm$ & $284.5 \pm 51.7^{*}$ \\
& 7.25 & 22.87 & \\
Triglyceride $(\mathrm{mg} / \mathrm{dl})$ & $72.08 \pm$ & $107.42 \pm$ & $64.89 \pm$ \\
& 5.21 & 10.97 & $5.85^{* *}$ \\
HDL $(\mathrm{mg} / \mathrm{dl})$ & $40.78 \pm$ & $12.65 \pm 2.76$ & $21.1 \pm 2.9$ \\
& 6.38 & & \\
LDL $(\mathrm{mg} / \mathrm{dl})$ & $12.37 \pm$ & $404.39 \pm 21.0$ & $250.3 \pm 52.2^{*}$ \\
& 9.44 & & \\
TC/HDL ratio & $1.84 \pm 0.38$ & $39.67 \pm 7.28$ & $14.81 \pm 3.5^{*}$ \\
Atherogenic index & $0.71 \pm 0.16$ & $26.31 \pm 3.31$ & $7.71 \pm 1.6^{* * *}$ \\
Glucose (mg/dl) & $88.85 \pm$ & $155.18 \pm$ & $125.8 \pm 12.9$ \\
& 5.32 & 10.56 & \\
Diet consumption g/day & $155.4 \pm 7.5$ & $122.3 \pm 8.4$ & $128.3 \pm 6.9$ \\
\% of change in body & $28.5 \pm 2.6$ & $55.9 \pm 6.5$ & $47.3 \pm 4.1$ \\
weight & & & \\
\hline
\end{tabular}

Vale shown are mean \pm S.E.M of 6 determinations

One-way ANOVA followed by Tukey post-test

${ }^{*} \mathrm{P}<0.05$, ${ }^{* *} \mathrm{P}<0.01$ and ${ }^{* *} \mathrm{P}<0.001$ compared to atherogenic group. 
glucose levels. The HDL-C was similar $(\mathrm{p}>0.05)$ to that in the atherogenic group. The leaves extract significantly prevented the gain in average body weight and increased daily diet consumption as compared to the atherogenic group. The data are summarized in Table 3.

\section{Effect of root extract on high fat diet-induced dyslipidemia}

The TC, triglyceride, LDL-C, TC/HDL ratio, atherogenic index and glucose levels in the atherogenic group were significantly increased as compared to the control group. Oral administration of root extract $(500 \mathrm{mg} / \mathrm{kg})$ with atherogenic diet prevented the rise in serum TC, LDL-C, TC/HDL ratio, atherogenic index and glucose levels. The treatment with $(500 \mathrm{mg} / \mathrm{kg})$ also increased HDL-C $(\mathrm{p}<0.05)$ as compared to the atherogenic group. The root extract significantly prevented the gain in average body weight and increased daily diet consumption as compared to the atherogenic group $(\mathrm{p}<0.001)$. The data are summarized in Table 4.

\section{Safety study}

The treatment with Morinda citrifolia fruit, leaves and root extracts for 10 day (tyloxapol study) and 6 weeks (high fat diet study) did not produce any death or behavioural changes in rats.

Acute toxicity testing (24 hour time) of Mc.Cr.F and Mc.Cr.L was conducted in mice at different doses (3, 5 and $10 \mathrm{~g} / \mathrm{kg}$ ) and there was no mortality or changes in gross behaviour observed up to the dose of as high as $10 \mathrm{~g} / \mathrm{Kg}$, as compared to control group. The roots extract (Mc.Cr.R) also did not cause any mortality and

Table 3 Effect of Morinda citrifolia leaves extract $(1000 \mathrm{mg} / \mathrm{kg})$ on high fat diet induced hyperlipidemia

\begin{tabular}{llll}
\hline Parameters & Control & Atherogenic & Treated \\
\hline Total cholesterol $(\mathrm{mg} / \mathrm{dl})$ & $81.02 \pm$ & $446.63 \pm 40.0$ & $235.3 \pm$ \\
& 10.1 & & $22.3^{* * *}$ \\
Triglyceride $(\mathrm{mg} / \mathrm{dl})$ & $70.94 \pm 5.2$ & $107.3 \pm 11.0$ & $70.52 \pm 11.0^{*}$ \\
$\mathrm{HDL}(\mathrm{mg} / \mathrm{dl})$ & $39.98 \pm$ & $13.26 \pm 3.14$ & $17.85 \pm 3.77$ \\
& 5.86 & & \\
LDL $(\mathrm{mg} / \mathrm{dl})$ & $25.85 \pm$ & $412.21 \pm 40.3$ & $203.38 \pm$ \\
& 10.7 & & $24.2^{* *}$ \\
TC/HDL ratio & $2.55 \pm 0.46$ & $37.37 \pm 8.56$ & $16.51 \pm 3.65^{*}$ \\
Atherogenic index & $1.17 \pm 0.41$ & $31.10 \pm 6.23$ & $15.51 \pm 3.65^{*}$ \\
Glucose $(\mathrm{mg} / \mathrm{dl})$ & $83.88 \pm$ & $158.81 \pm$ & $102.91 \pm$ \\
& 6.83 & 10.13 & $5.21^{*}$ \\
Diet consumption g/day & $150.91 \pm$ & $120.3 \pm 6.41$ & $140.8 \pm 9.3^{* *}$ \\
& 8.44 & & \\
\% of change in body & $25.04 \pm$ & $59.79 \pm 3.68$ & $26.50 \pm$ \\
weight & 2.42 & & $7.27^{* * *}$ \\
\hline
\end{tabular}

Vale shown are mean \pm S.E.M of 6 determinations One-way ANOVA followed by Tukey post-test

${ }^{*} \mathrm{P}<0.05$, ${ }^{* *} \mathrm{P}<0.01$ and ${ }^{* *} \mathrm{P}<0.001$ compared to atherogenic group.
Table 4 Effect of Morinda citrifolia root extract $(1000 \mathrm{mg} / \mathrm{kg}$ ) on high fat diet induced hyperlipidemia

\begin{tabular}{llll}
\hline Parameters & Control & Atherogenic & Treated \\
\hline Total cholesterol $(\mathrm{mg} / \mathrm{dl})$ & $70.67 \pm$ & $384.81 \pm$ & $224.5 \pm$ \\
& 5.76 & 32.99 & $26.6^{* * *}$ \\
Triglyceride $(\mathrm{mg} / \mathrm{dl})$ & $73.09 \pm$ & $109.42 \pm$ & $70.52 \pm$ \\
& 5.21 & 10.27 & $10.99^{*}$ \\
HDL $(\mathrm{mg} / \mathrm{dl})$ & $43.34 \pm$ & $11.49 \pm 3.26$ & $43.82 \pm 2.3^{* * *}$ \\
& 5.60 & & \\
LDL $(\mathrm{mg} / \mathrm{dl})$ & $18.71 \pm$ & $351.44 \pm$ & $173.21 \pm$ \\
& 5.21 & 32.90 & $2.0^{* * *}$ \\
TC/HDL ratio & $1.69 \pm 0.15$ & $52.01 \pm 16.11$ & $5.36 \pm 0.83^{* * *}$ \\
Atherogenic index & $0.70 \pm 0.2$ & $24.41 \pm 4.46$ & $5.74 \pm 2.11^{* * *}$ \\
Glucose (mg/dl) & $93.39 \pm 5.4$ & $157.67 \pm 9.4$ & $95.09 \pm 9.0^{* * *}$ \\
Diet consumption g/day & $160.04 \pm$ & $118.3 \pm 9.54$ & $135.4 \pm 8.7^{* * *}$ \\
& 5.5 & & \\
\% of change in body & $30.5 \pm 2.63$ & $55.19 \pm 4.58$ & $17.34 \pm 3.4^{* * *}$ \\
weight & & & \\
\hline
\end{tabular}

Vale shown are mean \pm S.E.M of 6 determinations

One-way ANOVA followed by Tukey post-test

${ }^{*} \mathrm{P}<0.05$ and ${ }^{* *} \mathrm{P}<0.001$ compared to atherogenic group.

changes in gross behaviour up to the dose of $10 \mathrm{~g} / \mathrm{Kg}$ as previously described [9].

\section{Discussion}

Morinda citrifolia has been considered useful in cardiovascular diseases particularly hypertension, atherosclerosis and dyslipidemia. In this study we used different animal models to evaluate the possible mode of action (s) of antidyslipidemic effect of different parts of Morinda citrifolia. Tyloxapol is a non-ionic surfactant being widely used to explore possible mechanism of lipid lowering drugs, it causes drastic increase in serum triglycerides and cholesterol levels due to increase in hepatic cholesterol synthesis particularly by the increase in HMG Co-A (3-hydroxy-3-methyl-glutaryl Co-A) activity [19] and by the inhibition of lipoprotein lipase responsible for hydrolysis of plasma lipids [20]. In fasting condition the only source of serum lipid levels is the endogenous production. Significant inhibition of rise in lipid levels by extracts of various parts of Morinda citrifolia in this model is indicative of inhibition of cholesterol biosynthesis by inhibition of HMG Co-A. This enzyme plays a key role in controlling lipid levels in plasma and other tissue. Most of the newer antidyslipidemic drugs such as statins act via the inhibition of HMG Co-A. However, failure of the Noni extracts to cause complete inhibition indicates the involvement of additional mechanisms. Morinda citrifolia is reported to be rich in flavones $[9,21,22]$, which are known to inhibit lipid biosynthesis [23]. High cholesterol diet induces endothelial dysfunction, atherosclerosis [24] and increases oxidative stress by increasing the expression of oxidation-sensitive genes, such as Elk-1 and p-CREB 
[25]. High cholesterol diet with cholic acid increases TC, LDL-C, atherogenic index and decrease HDL-C by enhancing intestinal absorption and secretion and decreasing catabolism of cholesterol [26]. Treatment with Morinda citrifolia extracts caused a significant decrease in mean serum TC and LDL-C while increased HDL-C. The plant extracts also caused significant reduction in the atherogenic index, which is considered a better indicator of coronary heart disease risk than individual lipoprotein concentration [27].

High fat diet also causes oxidative stress (enzymatic and non-enzymatic) in rats, thus, increases oxidation of low density lipoprotein (LDL) which plays key role in genesis of atherosclerosis. Antioxidants are known to effectively prevent this kind of damage [28]. The presence of strong antioxidant activities in various parts of Morinda citrifolia [29] may offer additional benefit in combating the oxidative stress caused by high cholesterol. Relatively strong antidyslipidemic activity in root extract may be due to the presence of more antioxidant activity in this part $[10,29]$. The active constituents responsible for antioxidant activity include 3,3'-bisdemethylpinoresinol, americanol A, morindolin, isoprincepin [30], scopoletin [31], kaempferol, ursolic acid, quercetin and various other constituents [30,32-34] [see additional file 1]

\section{Conclusions}

The present study provides mechanisms of antidyslipidemic activities of various parts of Morinda citrifolia through multiple pathways i.e., inhibition of biosynthesis, absorption and secretion of lipids. This may be due to the presence of multiple potent antioxidant constituents in this plant, though additional mechanism(s) cannot be ruled out. The results from this study rationalize the medicinal use of Morinda citrifolia in dyslipidemia and it can be used as a potential medicine for cardiovascular diseases. However, further studies are required to prove the safety and efficacy of Morinda citrifolia and its constituents in actual clinical settings.

\section{Additional material}

Additional file 1: Chemical constituents from various parts of Morinda Citrifolia. Following list shows reported chemical constituents isolated from different parts of Morinda citrifolia plant.

\section{Abbreviations}

(MC.CR.F): Morinda citrifolia fruit extract; (MC.CR.L): Morinda citrifolia leaves extract; (MC.CR.R.): Morinda citrifolia root extract; (TC): total cholesterol; (TG): triglyceride; (LDL-C): low density lipoprotein-cholesterol; (HDL-C): high density lipoprotein-cholesterol; (SD): Sprague-Dawley.
\end{abstract}

\section{Author details}

'Natural Product Research Division, Department of Biological and Biomedical Sciences, Aga Khan University Medical College, Karachi 74800, Pakistan.
2Department of Pharmacy, University of Baluchistan, Sariab Road, Quetta, Pakistan. ${ }^{3}$ King Saud University, Riyadh, Saudi Arabia.

\section{Authors' contributions}

SRM carried out the experimental work, data collection and evaluation, literature search and draft preparation. AHG identified the plant, raised funds, supervised the work and refined the manuscript for publication. NA responsible for critical review, intellectual input in discussion and overall presentation of paper. All authors have read and approved the final manuscript.

\section{Competing interests}

The authors declare that they have no competing interests.

Received: 25 June 2010 Accepted: 20 August 2010

Published: 20 August 2010

\section{References}

1. Paccaud F, Fasmeye VS, Wietlisbach V, Bovet P: Dyslipidemia and abdominal obesity: an assessment in three general populations. I Clin Epidemiol 2000, 53(4):393-400.

2. Ballantyne CM: Treatment of Dyslipidemia to Reduce Cardiovascular Risk in Patients with Multiple Risk Factors. Clin Cornerstone 2007, 8(6):S6-S13.

3. Grundy SM, Cleeman Jl, Merz CN, Brewer HB, Clark LT, Hunninghake DB, Pasternak RC, Smith SC, Stone NJ: National Heart, Lung, and Blood Institute; American College of Cardiology Foundation; American Heart Association. Implications of recent clinical trials for the National Cholesterol Education Program Adult Treatment Panel III guidelines. Circulation 2004, 110(2):227-239.

4. Wang MY, West BJ, Jensen CJ, Nowicki D, Chen SU, Palu AK, Anderson G: Morinda citrifolia (Noni) A literature review and recent advances in Noni research. Acta Pharmacologica Sinica 2002, 23(12):1127-1141.

5. Harada S, Hamabe W, Kamiaya K, Satake T, Yamamoto J, Tokuyama S: Preventive Effect of Morinda citrifolia Fruit Juice on Neuronal Damage Induced by Focal Ischemia. Biol Pharm Bull 2009, 32(3):405-409.

6. Nayak BS, Sandiford S, Maxwell A: Evaluation of the Wound-healing Activity of Ethanolic Extract of Morinda citrifolia L. Leaf. Evid Based Complement Alternat Med 2009, 6(3):351-356.

7. Takashima J, Ikeda Y, Komiyama K, Hayashi M, Kishida A, Ohsaki A: New Constituents from the Leaves of Morinda citrifolia. Chem Pharm Bull 2007, 55(2):343-345.

8. Runnie I, Salleh MN, Mohamed S, Head RJ, Abeywardena MY: Vasorelaxation induced by common edible tropical plant extracts in isolated rat aorta and mesenteric vascular bed. J Ethnopharmacol 2004, 92(2-3):311-316.

9. Gilani AH, Mandukhail SR, lqbal J, Yasinzai M, Aziz N, Khan A, Rehman N: Antispasmodic and vasodilator activities of Morinda citrifolia root extract are mediated through blockade of voltage dependent calcium channels. BMC Complement Altern Med 2010, 10:2.

10. Zin ZM, Hamid AA, Osman A: Antioxidative activity of extracts from Mengkudu (Morinda citrifolia L.) root, fruit and leaf. Food Chem 2002, 78:227-231.

11. Furusawa E, Hirazumi A, Story S, Jensen J: Antitumour potential of a polysaccharide-rich substance from the fruit juice of Morinda citrifolia (Noni) on sarcoma 180 ascites tumour in mice. Phytother Res 2003, 17(10):1158-64.

12. Shinya $Y$, Juno $\mathrm{O}$, Masanobu $\mathrm{S}$, Isafumi M, Yasuhiro O, Yoji T: Inhibition of angiotensin I converting enzyme by Noni [Morinda citrifolia] juice. Journal of the Japanese Society for Food Science and Technology 2002, 49(9):624-627.

13. Nolting J, Cheerva A, Jensen J, Anderson G, Nowicki D, Story S: The effects of Morinda citrifolia (Noni) fruit juice on serum cholesterol and triglyceride in current smokers. Circulation 2006, 113:301-381.

14. National Research Council: Guide for the Care and Use of Laboratory Animals Washington: National Academy Press 1996.

15. Ichihashi T, Izawa M, Miyata K, Mizui T, Hirano K, Takagishi Y: Mechanism of hypocholesterolemic action of S-8921 in rats: S-8921 inhibits ileal bile acid absorption. J Pharmacol Exp Ther 1998, 284(1):43-50.

16. Khanna AK, Rizvi F, Chander R: Lipid lowering activity of Phyllanthus niruri in hyperlipemic rats. J Ethnopharmacol 2002, 82(1):19-22. 
17. Berroughui H, Ettaib A, Gonzalez H, Alvarez de Sotomayor M, BennariKabchi N, Hmamouchi M: Hypolipidemic and hypocholesterolemic effect of argan oil (Argania spinosa L.) in Meriones Shawi rats. J Ethnopharmacol 2003, 89(1):15-18.

18. Aziz N, Mehmood MH, Mandukhail SR, Bashir S, Raoof S, Gilani AH: Antihypertensive, antioxidant, antidyslipidemic and endothelial modulating activities of a polyherbal formulation (POL-10). Vascul Pharmacol 2009, 50(1-2):57-64.

19. Kuroda M, Tanzawa K, Tsujita Y, Endo A: Mechanism for elevation of hepatic cholesterol synthesis and serum cholesterol levels in Triton WR1339-induced hyperlipidemia. Biochim Biophys Acta 489(1):119-125.

20. Schotz MC, Scanu A, Page IH: Effect of Triton on lipoprotein lipase of rat plasma. Am J Physiol 1957, 188(2):399-402.

21. Nandhasri P, Pawa KK, Kaewtubtim J, Jeamchanya C, Jansom C, Sattaponpun C: Nutraceutical properties of Thai "Yor" Morinda citrifolia and "Noni" juice extract. Songklanakarin J Sci Technol 2005, 27(2):579-586.

22. Ramamoorthy PK, Bono A: Antioxidant activity, total phenolic and flavonoid content of Morinda citrifolia fruit extracts from various extraction processes. J Engineering Sci Technol 2007, 2(1):70-80.

23. Glasser G, Graefe EU, Struck F, Veit M, Gebhardt R: Comparison of antioxidative capacities and inhibitory effects on cholesterol biosynthesis of quercetin and potential metabolites. Phytomedicine 2002, 9(1):33-40.

24. Hayashi T, Ishikawa T, Naito M, Kuzuya M, Funaki C, Asai K, Kuzuya F: Low level hyperlipidemia impairs endothelium-dependent relaxation of porcine coronary arteries by two mechanisms. Functional change in endothelium and impairment of endothelium-dependent relaxation by two mediators. Atherosclerosis 1991, 87(1):23-38.

25. de Nigris F, Lerman A, Ignarro LJ, Williams-Ignarro S, Sica V, Baker AH, Lerman LO, Geng YJ, Napoli C: Oxidation-sensitive mechanisms, vascular apoptosis and atherosclerosis. Trends Mol Med 2003, 9(8):351-359.

26. Heuman DM, Vlahcevic ZR, Bailey ML, Hylemon PB: Regulation of bile acid synthesis. II. Effect of bile acid feeding on enzymes regulating hepatic cholesterol and bile acid synthesis in the rat. Hepatology 1988, 8(4):892-897.

27. Vijayakumar RS, Surya D, Nalini N: Antioxidant efficacy of black pepper (Piper nigrum L.) and piperine in rats with high fat diet induced oxidative stress. Redox Rep 2004, 9(2):105-110.

28. Kinosian B, Glick H, Garland G: Cholesterol and Coronary Heart Disease: Predicting Risks by Levels and Ratios. J investig Med 1995, 43(5):443-450.

29. Krishnaiah D, Sarbatly R, Neh NL: Recovery of phytochemical components from various part of Morinda citrifolia extracts by using member separator. J Appl Sci 2007, 7(15):2093-2098.

30. Kamiya K, Tanaka Y, Endang H, Umar M, Satake T: Chemical constituents of Morinda citrifolia fruits inhibit copper-induced low-density lipoprotein oxidation. J Agric Food Chem 2004, 22;52(19):5843-8.

31. Shaw CY, Chen CH, Hsu CC, Chen CC, Tsai YC: Antioxidant properties of scopoletin isolated from Sinomonium acutum. Phytother Res 2003 17(7):823-5

32. Takashima J, Ikeda Y, Komiyama K, Hayashi M, Kishida A, Ohsaki A: New constituents from the leaves of Morinda citrifolia. Chem Pharm Bull (Tokyo) 2007, 55(2):343-5.

33. Kamiya K, Hamabe W, Harada S, Murakami R, Tokuyama S, Satake T: Chemical constituents of Morinda citrifolia roots exhibit hypoglycemic effects in streptozotocin-induced diabetic mice. Biol Pharm Bull 2008, 31(5):935-8.

34. Sattar FA: Studies On The Chemical Constituents Of Various Parts Of Morinda Citrifolia Linn.(Noni). PhD thesis. H.E.J. Research Institute of Chemistry/University of Karachi 1995 [http://eprints.hec.gov.pk/2274/1/2129. $\mathrm{htm}$.

doi:10.1186/1476-511X-9-88

Cite this article as: Mandukhail et al:: Studies on antidyslipidemic effects of Morinda citrifolia (Noni) fruit, leaves and root extracts. Lipids in Health and Disease 2010 9:88.

\section{Submit your next manuscript to BioMed Central and take full advantage of:}

- Convenient online submission

- Thorough peer review

- No space constraints or color figure charges

- Immediate publication on acceptance

- Inclusion in PubMed, CAS, Scopus and Google Scholar

- Research which is freely available for redistribution

Submit your manuscript at www.biomedcentral.com/submit
Biomed Central 